\title{
Immediate and Long-Term Therapy of Patients with Acute Coronary Syndromes with Thienopyridines. Current Status According to the Latest European Society of Cardiology (ESC) Guidelines
}

\author{
Sigmund Silber, M.D., Ph.D., F.A.C.C., F.E.S.C.**
}

Heart Center at the Isar, Munich, Germany

\begin{abstract}
For patients with acute coronary syndrome (ACS), the first priority is to alert emergency services. In addition to an ECG (ideally taken during the first medical contact at the patient's home), the key of life saving is the immediate antithrombotic therapy with acetylsalicylic acid (ASA) and (unless contraindicated) an injection of unfractionated heparin or bivalirudin as an alternative anticoagulant. Dual antiplatelet therapy (ASA combined with other antiplatelet drugs, like thienopyridines) should be started as soon as possible in the ambulance or at the latest in the hospital. For clopidogrel, a loading dose of 600 $\mathrm{mg}$ is the standard. To avoid the risk of an unknown low or missing clopidogrel response, prasugrel is recommended instead, with administration of a loading dose of $60 \mathrm{mg}$, if no contraindication (s/p stroke or TIA) exists. When PCI is planned, the ambulance must head directly to the nearest hospital with continuous (24/7) PCI service within 90 (to 120) minutes. The maintenance dose for clopidogrel is $75 \mathrm{mg} / \mathrm{d}$; a daily double-dose has not proven to be superior, even in "low responders". For prasugrel, the
\end{abstract}

Abbreviations: ACS, acute coronary syndromes; ASA, acetylsalicylic acid; DAPT, dual antiplatelet therapy; ECG, electrocardiogram; ESC, European Society of Cardiology; NSTE-ACS, non-ST-elevation acute coronary syndrome; NSTEMI, non-ST-elevation myocardial infarction; PCI, percutaneous coronary intervention; STEMI, ST-segment elevation myocardial infarction; TIA, transient ischemic attack; UAP, unstable angina pectoris.

Citation: Silber S. Immediate and Long-Term Therapy of Patients with Acute Coronary Syndromes with Thienopyridines. Current Status According to the Latest European Society of Cardiology (ESC) Guidelines. RMMJ 2011;2(3):eo056. doi:10.5041/RMMJ.10056

Copyright: (C) 2011 Sigmund Silber. This is an open-access article. All its content, except where otherwise noted, is distributed under the terms of the Creative Commons Attribution License (http://creativecommons.org/licenses/by/3.o), which permits unrestricted use, distribution, and reproduction in any medium, provided the original work is properly cited.

Conflict of interest: Professor Silber received speaker's honoraria as well as advisory board fees from Sanofi-Aventis, Daiichi-Sankyo and Lilly.

* E-mail: sigmund@silber.com 
maintenance dose is usually $10 \mathrm{mg} / \mathrm{d}$. To avoid bleeding complications in patients $\geq 75 \mathrm{y}$ and/or $<60$ $\mathrm{kg}$, a prasugrel maintenance dose of $5 \mathrm{mg} / \mathrm{d}$ is recommended. The ESC guidelines recommend DAPT for 1 year after ACS in all patients - independent of the type of ACS and independent of whether any or which coronary stent has been implanted. With DAPT, the patient - and not the stent - is treated.

KEY WORDS: Acute coronary syndrome, myocardial infarction, clopidogrel, prasugrel, percutaneous coronary intervention, stent

\section{BACKGROUND}

Despite the extensive scientific knowledge of cardiovascular risk factors and despite educating the general public, cardiovascular diseases continue to be the leading cause of death. Patients with acute coronary syndromes (ACS) are at particular risk. The immediate measures initiated in these patients often determine if the outcome is life or death. The objective of this overview is the evaluation of the current guidelines to effect practical therapy tips for primary and secondary health care providers, with special focus on the antiplatelet treatment with thienopyridines.

\section{DEFINITION OF ACUTE CORONARY SYNDROME}

Depending on the symptoms and objective findings, ACS comprises three distinct syndromes (Table 1): acute myocardial infarction with persistent ST-segment elevation (STEMI), acute myocardial infarction without ST-segment elevation
(NSTEMI), and unstable angina pectoris (UAP). NSTEMI and UAP are often combined to NSTEACS. A (presumably) new-onset left bundle branch block (LBBB) is - depending on the symptoms - initially to be regarded as a STEMI. For STEMI, the symptoms and the electrocardiogram (ECG) are sufficient for diagnosis; one does not have to wait for the results of troponin or CK-MB. In an ideal setting with short system delay times, troponin, if determined, would be negative anyway within the first 6 hours after onset of symptoms. For NSTE-ACS, a positive troponin is the first determining factor for NSTEMI (Table 1, Figure 1).

\section{PRE-HOSPITAL EMERGENCY MEASURES}

The first priority is to alert emergency services whatever emergency number applies geographically. In addition to general measures including an ECG (ideally taken during the first medical

Table 1. Definition of the three forms of acute coronary syndromes (ACS).

\begin{tabular}{lccc}
\hline & STEMI & NSTEMI & Unstable angina \\
\hline ACS symptoms & + & + & + \\
ECG & ST-elevation or new & with or without ST- \\
depression & $\begin{array}{c}\text { with or without ST- } \\
\text { depression }\end{array}$ \\
Troponin & (usually still) negative & positive & negative \\
Myocardial infarction & yes & yes & no \\
& (based on ST-elevation) & (based on troponin) & \\
\hline
\end{tabular}

STEMI, ST-segment elevation myocardial infarction; NSTEMI, non-ST-elevation myocardial infarction; LBBB, left bundle branch block. 
contact at the patient's home), the key is the immediate antithrombotic therapy: if possible (independent of any history of pre-existing therapy), acetylsalicylic acid (ASA) $500 \mathrm{mg}$ and (unless contraindicated) an injection of 5,000 IU of unfractionated heparin should be immediately administered. Other dosing or oral administration of ASA - within the frame of the new European Society of Cardiology (ESC) guidelines - may also be applied, depending on local practice. If already available at first medical contact, a bolus of bivalirudin can be preferred as an initial alternative to unfractionated heparin (Class IB vs. IC). If the transportation times to the next hospital are short, additional antiplatelet therapy with a thienopyridine can be administered in the hospital. There is no need for "upstream" infusion of gly- coprotein IIb/IIIa inhibitors such as abciximab, integrelin, or tirofiban (Class III B).

Of utmost importance is the decision - if possible at a pre-hospital stage - whether a percutaneous coronary intervention (PCI) can or should be performed (Figure 2). When a PCI is planned, the ambulance must head directly to the nearest hospital with continuous (24/7) PCI service (Figure 2) within 90 (to 120) minutes.

\section{IMMEDIATE MEASURES IN THE HOSPITAL}

The basis for optimal oral antithrombotic therapy is a dual antiplatelet therapy (DAPT), which is the

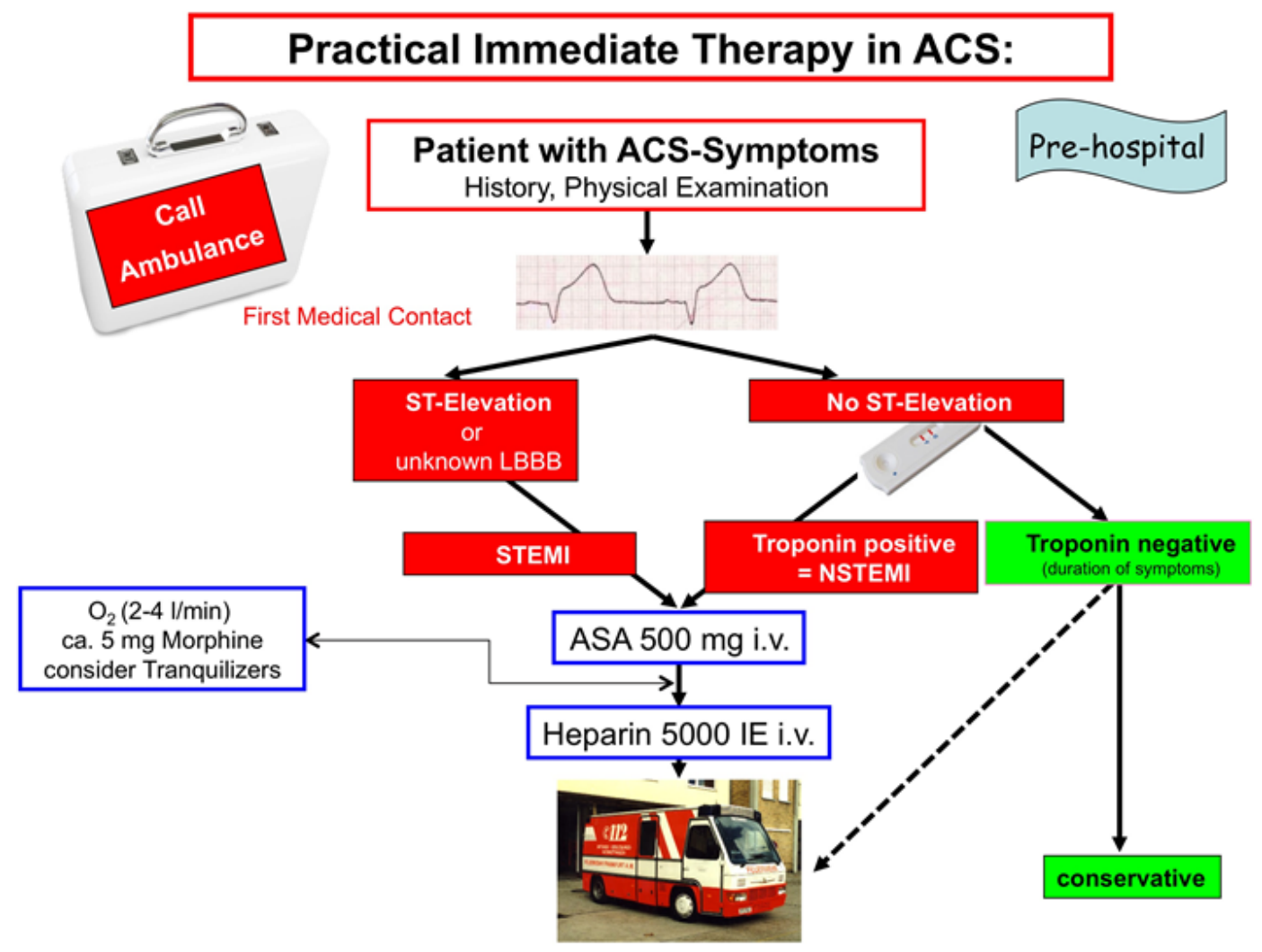

Figure 1. Suggestion for immediate pre-hospital measures in patients with acute coronary syndromes (ACS). Other dosing or oral administration of acetylsalicylic acid (ASA) - within the frame of the new European Society of Cardiology (ESC) guidelines - may also be applied, depending on local practice. (LBBB, left bundle branch block; NSTEMI, non-ST-elevation myocardial infarction; STEMI, ST-segment elevation myocardial infarction.) 


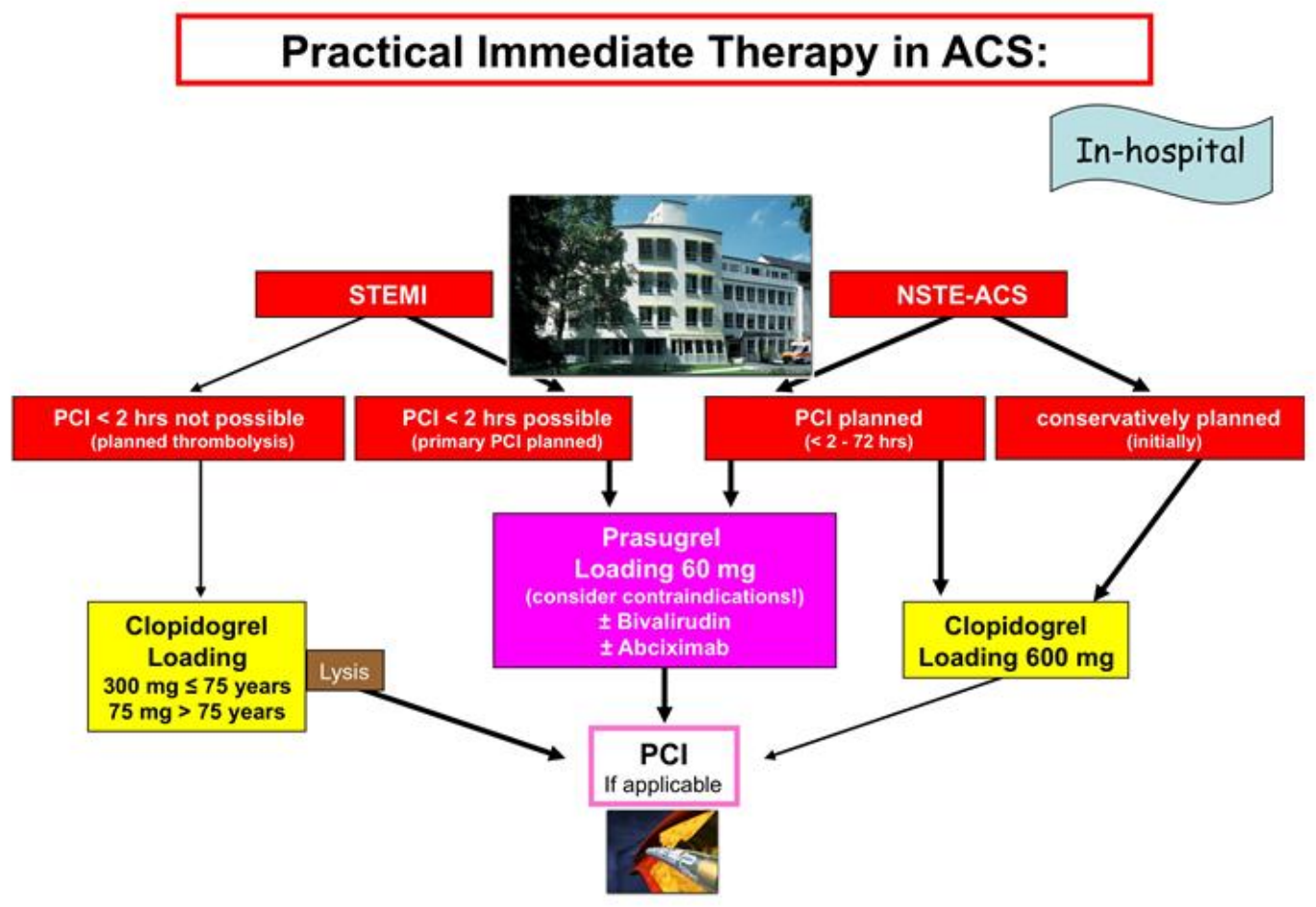

Figure 2. Suggestion for in-hospital therapy of patients with acute coronary syndromes (ACS). If transportation times are too long, then the thienopyridine loading dose should be administered pre-hospital, depending on the planned reperfusion strategy. If thrombolysis is planned, the initial clopidogrel dose depends on age. (PCI, percutaneous coronary intervention; STEMI, ST-segment elevation myocardial infarction; NSTEMI, non-ST-elevation myocardial infarction.)

combination of ASA with a thienopyridine derivate, i.e. with clopidogrel or prasugrel (ticlopidine is no longer recommended). The data for clopidogrel regarding DAPT for STEMI come mainly from the CLARITY and COMMIT-CCS2 trials (not PCI studies) and regarding NSTE-ACS from the CURE study. These trials were performed using the original clopidogrel hydrogen sulfate. The clinical effect and safety of so-called "generics" (besylate or other compounds) are not established and therefore not recommended.

For prasugrel, the scientific foundation is mainly the TRITON-TIMI 38 trial for all forms of ACS. In this PCI trial the primary combined endpoint of cardiovascular death, non-fatal myocardial infarction, and non-fatal stroke was reached in favor of prasugrel (Table 2). On the other hand, the rate of major bleeding was significantly higher with prasugrel as compared to clopidogrel (Table 2). More details, especially the significant reduction of stent thrombosis with prasugrel, are listed in Table 2. Total mortality was relatively low in both groups (Table 2). The advantage of prasugrel was especially pronounced in patients with STEMI (Table 2) or diabetes mellitus (significant reduction of composite primary end-point from $17.0 \%$ to $12.2 \%)$. In patients with STEMI or diabetes mellitus, this clinical advantage was achieved without a significant difference in major bleeding complications (for STEMI, see Table 2; in diabetic patients it was $2.6 \%$ for clopidogrel and $2.5 \%$ for prasugrel).

Patients with STEMI - and thus destined for primary PCI - should follow the recent guidelines 
Table 2. Results of the randomized TRITON-TIMI 38 study. At 15 months, the primary efficacy end-point, a combination of cardiovascular death, non-fatal myocardial infarction, and non-fatal stroke, was reached in favor of prasugrel. The key safety end-point, non-CABG-related TIMI major bleeding, is also listed (in STEMI not significant). For more details, please see text.

\begin{tabular}{lcccccc}
\hline & $\begin{array}{c}\text { Clopidogrel } \\
\text { total } \\
(n=6795)\end{array}$ & $\begin{array}{c}\text { Prasugrel } \\
\text { total } \\
(n=6813)\end{array}$ & $\begin{array}{c}\text { Clopidogrel } \\
\text { STEMI } \\
(n=1765)\end{array}$ & $\begin{array}{c}\text { Prasugrel } \\
\text { STEMI } \\
(n=1769)\end{array}$ & $\begin{array}{c}\text { Clopidogrel } \\
\text { NSTE-ACS } \\
(n=5030)\end{array}$ & $\begin{array}{c}\text { Prasugrel } \\
\text { NSTE-ACS } \\
(n=5044)\end{array}$ \\
\hline $\begin{array}{l}\text { Primary end- } \\
\text { point }\end{array}$ & $12.1 \%$ & $9.9 \%^{*}$ & $12.4 \%$ & $10.0 \%^{*}$ & $12.1 \%$ & $9.9 \%^{*}$ \\
$\begin{array}{l}\text { Total mortality } \\
\text { Non-fatal }\end{array}$ & $3.2 \%$ & $3.0 \%$ & $4.3 \%$ & $3.3 \%$ & $2.4 \%$ & $2.6 \%$ \\
$\begin{array}{l}\text { myocardial } \\
\text { infarction }\end{array}$ & $9.5 \%$ & $7.3 \%^{*}$ & $9.0 \%$ & $6.8 \%^{*}$ & $9.8 \%$ & $7.5 \%^{*}$ \\
$\begin{array}{l}\text { Stent } \\
\text { thrombosis }\end{array}$ & $2.4 \%$ & $1.1 \%^{*}$ & 2.8 & $1.6^{*}$ & $2.2 \%$ & $1.0 \%^{*}$ \\
$\begin{array}{l}\text { TIMI major } \\
\text { bleeding }\end{array}$ & $1.8 \%$ & $2.4 \%^{*}$ & $2.1 \%$ & $2.4 \%$ & $1.6 \%$ & $2.4 \%^{*}$ \\
\hline
\end{tabular}

${ }^{*} P<0.05$.

of the ESC, i.e. DAPT preferably with prasugrel (6o mg loading dose, regardless of age and weight) (Figure 2; level of recommendation for prasugrel = I B, for clopidogrel = I C). The 30-day mortality rate could hereby be significantly reduced: from $2.6 \%$ with clopidogrel to $1.6 \%$ with prasugrel. For STEMI as well as for NSTE-ACS, prasugrel was able to reduce significantly both the non-fatal myocardial infarction and stent thrombosis (Table 2). Due to the significant increase of fatal bleeding ( $0.1 \%$ versus $0.4 \%$ ), a history of previous stroke or transient ischemic attack (TIA), however, is a contraindication for prasugrel.

However, in the group of patients with no history of stroke or TIA, age $<75$ years, and/or body weight $\geq 60 \mathrm{~kg}$, non- coronary artery bypass graft surgery CABG-related thrombolysis in myocardial infarction (TIMI) major bleeding was no longer significantly different between prasugrel (2.0\%) and clopidogrel (1.5\%). In this group, the primary efficacy end-point was still significantly reduced with prasugrel (from $11 \%$ to 8.3\%; $P<0.001)$.

For NSTE-ACS with planned PCI, either prasugrel (IIa B) or clopidogrel (IC) may be administered (Figure 2). Recently, the new USAguidelines 2011 upgraded prasugrel for planned PCI in NSTE-ACS to a Class IB recommendation.

\section{LONG-TERM TREATMENT AFTER ACUTE CORONARY SYNDROME}

The maintenance dose for clopidogrel is $75 \mathrm{mg} / \mathrm{d}$; a daily double-dose has not proven to be superior, even in "low responders". For prasugrel, the maintenance dose is usually $10 \mathrm{mg} / \mathrm{d}$. To avoid bleeding complications in patients $\geq 75 \mathrm{y}$ and/or $<60 \mathrm{~kg}$, a prasugrel maintenance dose of $5 \mathrm{mg} / \mathrm{d}$ is recommended. Since the efficacy of prasugrel is independent of genetic factors, a genetic test or in-vitro platelet function test for prasugrel is not necessary. A possible interaction of proton pump inhibitors (PPI) with clopidogrel is still debated, but prasugrel seems to be independent of this postulated interaction. The ESC guidelines recommend DAPT for 1 year after ACS in all patients - independent of the type of ACS and independent of whether any or which coronary stent has been implanted. With DAPT, the patient and not the stent - is treated. 


\section{BIBLIOGRAPHY}

Abraham NS, Hlatky MA, Antman EM, et al. ACCF/ ACG/AHA 2010 Expert Consensus Document on the Concomitant Use of Proton Pump Inhibitors and

Thienopyridines: A Focused Update of the ACCF/ ACG/AHA 2008 Expert Consensus Document on Reducing the Gastrointestinal Risks of Antiplatelet Therapy and NSAID Use. Circulation 2010;122:2619-33. doi:10.1161/CIR.ob013e318202f701

Bhatt DL, Cryer BL, Contant CF, et al. Clopidogrel with or without omeprazole in coronary artery disease. N Engl J Med 2010;363:1909-17. doi:10.1056/ NEJ$\underline{\text { Moa1007964 }}$

Mega JL, Close SL, Wiviott SD, et al. Cytochrome p450 polymorphisms and response to clopidogrel. $\mathrm{N}$ Engl J Med 2009;360:354-62. doi:10.1056/NEJM oa o809171

Mega JL, Close SL, Wiviott SD, et al. Genetic variants in $\mathrm{ABCB} 1$ and $\mathrm{CYP}_{2} \mathrm{C} 19$ and cardiovascular outcomes after treatment with clopidogrel and prasugrel in the TRITON-TIMI 38 trial: a pharmacogenetic analysis. Lancet 2010;376:1312-9. doi:10.1016/So140-6736 (10)61273-1

Mehta SR, Tanguay JF, Eikelboom JW, et al. Doubledose versus standard-dose clopidogrel and high-dose versus low-dose aspirin in individuals undergoing percutaneous coronary intervention for acute coronary syndromes (CURRENT-OASIS 7): a randomised factorial trial. Lancet 2010;376:1233-43. doi:10.1016/ So140-6736(10)61088-4

Montalescot G, Wiviott SD, Braunwald E, et al. Prasugrel compared with clopidogrel in patients undergoing percutaneous coronary intervention for ST-elevation myocardial infarction (TRITON-TIMI 38): Doubleblind, randomised controlled trial. Lancet 2009;373:723-31. doi:10.1016/So140-6736(09)60 4 $41-4$

Serebruany VL. Mortality in the TRITON trial: update from the FDA prasugrel action package. Am J Cardiol 2010;105:1356-7. doi:10.1016/j.amjcard.2009.12.052

Sibbing D, Braun S, Morath T, et al. Platelet reactivity after clopidogrel treatment assessed with point-ofcare analysis and early drug-eluting stent thrombosis. J Am Coll Cardiol 2009;53:849-56. doi:10.1016/j. jacc.2008.11.030

Trenk D, Hochholzer W, Fromm MF, et al. Cytochrome $\mathrm{P} 450$ 2C19 681G $>$ A polymorphism and high onclopidogrel platelet reactivity associated with adverse1-year clinical outcome of elective percutaneous coronary intervention with drug-eluting or bare-metal stents. J Am Coll Cardiol 2008;51:1925-34. doi:10. 1016/j.jacc.2007.12.056

Widimsky P, Wijns W, Fajadet J, et al. Reperfusion therapy for ST elevation acute myocardial infarction in Europe: description of the current situation in 30 countries. Eur Heart J 2010;31:943-57. doi:10.1093 Leurheartj/ehp492

Wijns W, Kolh P, Danchin N, et al. Guidelines on myocardial revascularization: The Task Force on Myocardial Revascularization of the European Society of Cardiology (ESC) and the European Association for Cardio-Thoracic Surgery (EACTS). Eur Heart J 2010;31: 2501-55. doi:10.1093/eurheartj/ehq277

Wiviott SD, Antman EM, Braunwald E. Prasugrel. Circulatin 2010;122:394-403. doi:10.1161/ CIRCULATIONAHA.109.921502

Wiviott SD, Braunwald E, Angiolillo DJ, et al. Greater clinical benefit of more intensive oral antiplatelet therapy with prasugrel in patients with diabetes mellitus in the trial to assess improvement in therapeutic outcomes by optimizing platelet inhibition with prasugrel-Thrombolysis in Myocardial Infarction 38. Circulation 2008;118:1626-36. doi:10.1161/CIRCULAT IONAHA.108.791061

Wiviott SD, Braunwald $\mathrm{E}, \mathrm{McCabe} \mathrm{CH}$, et al. Intensive oral antiplatelet therapy for reduction of ischaemic events including stent thrombosis in patients with acute coronary syndromes treated with percutaneous coronary intervention and stenting in the TRITONTIMI 38 trial: a subanalysis of a randomised trial. Lancet 2008,371:1353-63. doi:10.1016/So140-673 6(08)60422-5

Wiviott SD, Braunwald E, McCabe $\mathrm{CH}$, et al. Prasugrel versus clopidogrel in patients with acute coronary syndromes. N Engl J Med 2007;357:2001-15. doi:10. 1056/NEJMoao706482

Wiviott SD, Trenk D, Frelinger AL, et al. Prasugrel compared with high loading- and maintenance-dose clopidogrel in patients with planned percutaneous coronary intervention: the Prasugrel in Comparison to Clopidogrel for Inhibition of Platelet Activation and Aggregation-Thrombolysis in Myocardial Infarction 44 trial. Circulation 2007;116:2923-32. doi:10.1161/ CIRCULATIONAHA.107.740324

Wright RS, Anderson JL, Adams CD et al. 2011 ACCF/AHA Focused Update of the Guidelines for the Management of Patients With Unstable Angina/NonST-Elevation Myocardial Infarction (Updating the 2007 Guideline) A Report of the American College of Cardiology Foundation/American Heart Association Task Force on Practice Guidelines Developed in Collaboration With the American College of Emergency 
Physicians, Society for Cardiovascular Angiography and Interventions, and Society of Thoracic Surgeons. J Am Coll Cardiol 2011;57:1920-59. doi:10.1016/j.jacc. $\underline{\text { 2011.02.009 }}$

Wright RS, Anderson JL, Adams CD et al. 2011 ACCF/AHA Focused Update of the Guidelines for the
Management of Patients With Unstable Angina/ NonST-Elevation Myocardial Infarction (Updating the 2007 Guideline): A Report of the American College of Cardiology Foundation/American Heart Association Task Force on Practice Guidelines. Circulation 2011;123:2022-6o. doi: 10.1161/CIR.obo13e3182 of2 f $3 \mathrm{e}$ 